\title{
Tecnologias Digitais e a relação entre teoria e prática: uma análise da produção em trinta anos de BOLEMA
}

\author{
Digital Technologies and the relationship between theory and practice: an \\ analysis of the literature in thirty years of BOLEMA
}

\author{
Marcelo de Carvalho Borba ${ }^{*}$ \\ Helber Rangel Formiga Leite de Almeida ${ }^{* *}$ \\ Aparecida Santana de Souza Chiari***
}

\begin{abstract}
Resumo
Neste artigo apresentamos uma análise das pesquisas envolvendo as Tecnologias Digitais e seu uso na sala de aula de Matemática no Brasil. Nosso cenário de investigação foi constituído pelas publicações que abordaram essa temática nos trinta anos de existência da revista BOLEMA. Como procedimentos metodológicos, realizamos a análise dos textos encontrados na busca por convergências entre eles, combinando elementos da pesquisa bibliográfica, estado da arte e da meta-análise. Identificamos dois tipos de relação entre teoria e prática, o primeiro no qual os autores, a partir de algumas atividades realizadas, teorizavam seus resultados e o segundo em que os autores, pautando-se em resultados de pesquisa, realizavam intervenções em sala de aula ou em outros ambientes educacionais. Entendemos que os artigos analisados indicam que, no contexto dos trabalhos publicados sobre Tecnologias Digitais, a pesquisa em Educação Matemática contempla constantemente teoria e prática de forma dinâmica, fugindo de extremos que oscilam entre o pragmatismo imediatista e a teorização pura.
\end{abstract}

Palavras-Chave: Estado da Arte. Meta-Análise. Educação Matemática. Tecnologias da Informação e Comunicação.

\begin{abstract}
This article presents an analysis of the research on the use of digital technologies in mathematics classes in Brazil. Our research was based on articles in BOLEMA that have addressed this issue over the past thirty years. Methodologically, we conducted an analysis of the texts seeking similarities between them, combining elements of literature review, state of the art, and meta-synthesis. We identified two types of relationships between theory and practice: the first one in which the authors started from some practical activities, ending with some theoretical results; and the second one in which the authors, based on research results, designed interventions in classroom or in other educational settings. The analysis suggests that, in the context of published articles about

\footnotetext{
* Doutor em Educação Matemática pela Cornell University e Livre Docente pela Universidade Estadual Paulista (UNESP/Rio Claro). Vinculado à Universidade Estadual Paulista (UNESP), Rio Claro, São Paulo, Brasil. Endereço para correspondência: Avenida 24 A, 1515, Bela Vista, CEP 13506-900, Rio Claro, São Paulo, Brasil. E-mail: mborba@rc.unesp.br.

** Doutorando em Educação Matemática pela Universidade Estadual Paulista (UNESP/Rio Claro). Professor da Universidade Federal de Campina Grande (UFCG), Pombal, Paraíba, Brasil. Endereço para correspondência: Rua Jairo Vieira Feitosa, s/no , CEP 58840-000, Pombal, Paraíba, Brasil. E-mail: helber.rangel@gmail.com.

*** Doutoranda em Educação Matemática pela Universidade Estadual Paulista (UNESP/Rio Claro). Vinculada à Universidade Federal de Mato Grosso do Sul (UFMS), Campo Grande, Mato Grosso do Sul, Brasil. Endereço para correspondência: Instituto de Matemática/INMA, Cidade Universitária, s/nº, 79090-900, Campo Grande, Mato Grosso do Sul, Brasil. E-mail: cidach@gmail.com.
} 
Digital Technologies, the research in mathematics education constantly contemplates theory and practice in a dynamic manner, avoiding the extremes of immediate pragmatism and pure theory.

Keywords: State of the Art. Meta-Synthesis. Mathematics Education. Information and Communication Technologies.

\section{Introdução}

Pesquisas e práticas efetivas em Educação Matemática é um tema que há muito aflige a comunidade de Educação Matemática em geral e, em particular, aquela vinculada ao Programa de Pós-Graduação em Educação Matemática (PPGEM) da UNESP, campus de Rio Claro - SP, sede do Boletim de Educação Matemática (BOLEMA). Um vínculo entre teoria e prática era algo que há muito preocupava docentes desse programa. Bicudo (1993) nos chama a atenção, há mais de duas décadas, para o fato de que as dissertações e teses não ficam na prateleira, com exceção daquelas que são produzidas com o único intuito da obtenção do título, de mestre ou doutor. Muito pelo contrário, boa parte delas serve como ponto de partida para outras pesquisas, além de serem lembradas em livros e artigos. No texto de Bicudo, que deu origem a boa parte da obra desta pesquisadora sobre o que é pesquisa, a autora faz uma importante distinção entre pesquisa, relato de experiência, proposta pedagógica e ação pedagógica ${ }^{1}$. Em seu artigo, a autora já demonstra a mesma preocupação que norteia esse número especial.

Ao distinguir pesquisa como sendo aquela que tem uma pergunta norteadora, em torno da qual se caminha em busca de uma resposta, a autora não a vê separada da prática, que ela denominou de ação pedagógica. Segundo Bicudo (1993), a ação pedagógica pode, e deve, se transformar em pesquisa. Em particular, a noção de pesquisa-ação é enfatizada para mostrar como a prática pode se tornar pesquisa. Embora existam traços do caminho inverso, ou seja, que a pesquisa influencia a prática e as propostas pedagógicas, não há uma ênfase muito forte em Bicudo (1993) nesse sentido.

Com base nisso, e na data comemorativa de 30 anos do BOLEMA, realizamos neste texto uma análise, a partir da combinação de elementos da revisão bibliográfica (LIMA; MIOTO, 2007), do estado da arte (FERREIRA, 2002) e da meta-análise (BICUDO, 2014), das pesquisas relacionadas às Tecnologias Digitais (TD) já publicadas no Boletim durante este período, buscando encontrar similaridades entre elas, no sentido de nos aproximar de

\footnotetext{
${ }^{1}$ Ação pedagógica e prática pedagógica são compreendidas por nós como sinônimos neste texto.
} 
contribuições no desenvolvimento de práticas pedagógicas efetivas do professor de Matemática.

Para tal, neste texto vamos analisar artigos publicados nos trinta anos de BOLEMA que digam respeito à Educação Matemática no Brasil, inseridos na temática das TD - tema pelo qual nosso grupo de pesquisa se interessa há mais de vinte anos - e que se relacionem a um dos sentidos apontados anteriormente (teoria para prática ou prática para teoria). Antes, porém, é importante que deixemos claro que não é preciso que haja uma ligação direta entre um relatório de pesquisa, tese ou artigo e a prática. Ter uma proposta para ser implementada em sala de aula do primeiro ano do ensino médio, por exemplo, é apenas uma das possibilidades entre o fazer pesquisa e a influência na prática. Há, ainda, artigos que não terminam com um produto, como boa parte dos artigos de Ubiratan D’Ambrósio, mas que provocaram possibilidades de mudanças nas salas de aula. Pode-se citar, como exemplo, que vários livros didáticos incorporam questões relacionadas à Matemática de outras comunidades que não aquela produzida por matemáticos, ou já discutem e propõem investigações para serem feitas com Tecnologias Digitais em geral.

Se, por um lado, a relação imediata entre teoria e prática não é o modelo único, é fundamental lembrar que a pesquisa em Educação Matemática surge da necessidade de se compreender os problemas ligados ao ensino e à aprendizagem de Matemática (D’AMBRÓSIO; BORBA, 2010). Temos que ter essa perspectiva em mente, evitando dois extremos que podem ser perniciosos para a Educação Matemática. No primeiro, evitarmos a pesquisa exotérica e verborrágica que confunde profundidade com excesso de palavras ou não compromisso com a prática. No outro, a visão que toda pesquisa deve, imediatamente, resolver um problema aparente da sala de aula, de forma imediata ou imediatista, sem permitir uma reflexão de maior fôlego que leve a pesquisas que desnaturalizem aspectos da educação que parecem intocáveis. Assim, a temática deste número especial do BOLEMA é bastante apropriada para que se reflita sobre a interação teoria e prática.

\section{GPIMEM e suas pesquisas}

A Educação Matemática - embora seja possível encontrar passos iniciais no sentido da formação de um novo campo de estudo, no início da década de 1970 - ganha força a partir da criação do PPGEM e de outros programas de pós-graduação (BICUDO, 1999; D’AMBRÓSIO; BORBA, 2010), principalmente em virtude de serem locais comuns a diversos pesquisadores preocupados com questões inicialmente relacionadas ao ensino e à 
aprendizagem de Matemática, o que favoreceu, por sua vez, a criação e fortificação de Grupos de Pesquisa vinculados a esses programas. Um destes grupos é o Grupo de Pesquisa em Informática, outras Mídias e Educação Matemática $\left(\mathrm{GPIMEM}^{2}\right)$, cujo objetivo é estudar questões ligadas às tecnologias na Educação Matemática, em particular o uso das Tecnologias Digitais (TD) na formação do professor de Matemática, na sua atuação em sala de aula ou, ainda, na maneira com que os alunos modificam seu pensamento a partir do contato com estas tecnologias. O GPIMEM vem investigando, sistematicamente, há mais de vinte anos, as diversas dimensões da presença dessas mídias na Educação Matemática.

Como o próprio nome do grupo propõe, embora haja um privilégio no olhar para a informática, analisamos, também, a escrita, a oralidade e as diversas formas de comunicação multimodal (SCUCUGLIA, 2012), nas quais se combinam outras formas de expressão, como texto usual, som, vídeo, diagramas e animações, por exemplo. Nosso grupo pensa nessas questões para responder a indagações da prática da sala de aula de hoje (JAVARONI et al., 2013), para ver como está sendo implementada na prática e como a sala de aula poderia vir a ser (BORBA, 2009, 2012). Fazemos também pesquisa sobre o uso do Facebook em sala de aula presencial e virtual (BORBA; SCUCUGLIA; GADANIDIS, 2014), ao mesmo tempo que tentamos entender o que se passa na sala de aula usual que não se abre para as Tecnologias Digitais. Fazemos este último tipo de pesquisa por contraste, ao analisarmos a sala de aula que muda, tentando enxergar como é a sala que não mudou, onde ministrávamos aula anteriormente.

Ainda que possa transparecer, o GPIMEM não se limita a trabalhos exclusivamente práticos. O grupo também desenvolve ideias de cunho teórico sobre como compreender a produção de conhecimento realizada pelo ser humano em interação com mídias, sejam elas digitais ou não (BORBA; VILLARREAL, 2005). Essa noção é sistematizada na metáfora seres-humanos-com-mídias e diversos trabalhos analisam como pode ser utilizada e ampliada no contexto da Educação Matemática. Recentemente, intersecções e novas ideias teóricas têm surgido quando o constructo seres-humanos-com-mídias é repensado a partir de ideias da Teoria da Atividade (SOUTO; BORBA, 2013; SOUTO, 2013; SOUTO; ARAÚJO, 2013).

Com base nesse histórico de interesse por diversos aspectos teóricos e práticos em relação às tecnologias e à Educação Matemática, neste trabalho buscamos nos aproximar das compreensões sobre relações entre as pesquisas dessa linha já publicadas no Boletim e a dialética teoria e prática ou prática e teoria. Pensamos que com esse trabalho, de certa forma,

\footnotetext{
${ }^{2}$ Disponível em: <http://www.rc.unesp.br/gpimem/index.php〉. Acesso em 13 abr. 2015.
} 
materializamos o que Bicudo (1993) inicialmente sugere: há movimentos em ambos os sentidos. No entanto, em seu texto não há menção a, por exemplo, o que difere os dois movimentos ou de que forma esses movimentos se concretizam, efetivamente, nas pesquisas desenvolvidas no Brasil na área de Educação Matemática, em particular aquelas preocupadas com as tecnologias. Buscamos destacar esses elementos neste trabalho.

\section{Metodologia e processos metodológicos utilizados}

Nossa pesquisa, de caráter teórico, foi guiada por elementos da pesquisa bibliográfica, do estado da arte e da meta-análise, em um processo que combinamos essas três abordagens metodológicas na busca por indícios que identificassem os caminhos das pesquisas envolvendo teoria e prática em Educação Matemática, associadas ao uso de Tecnologias Digitais, nos 30 anos da revista BOLEMA. Compreendemos a pesquisa bibliográfica como um procedimento metodológico utilizado na busca de soluções para um problema de pesquisa. Lima e Mioto (2007) salientam que nessa abordagem é necessária a escolha do método de pesquisa empregado, expor a maneira como ocorreu a construção do desenho metodológico e a escolha pelos procedimentos utilizados. Para a análise mencionada nas seções anteriores, realizamos um estado da arte (FERREIRA, 2002) a partir de dois exercícios de interpretação dos títulos e resumos de todos os artigos publicados no BOLEMA desde sua criação, em 1985. No primeiro olhar, buscamos catalogar todos os trabalhos que se relacionassem, de alguma forma, com as tecnologias. Com esse primeiro olhar, reunimos 36 artigos, apresentados nas seções seguintes.

Primeiramente, em um quadro analítico, organizamos informações relacionadas aos textos, catalogamos seus autores, os títulos, o ano de publicação, o volume e número do BOLEMA em que foram publicados. Também, escrevemos a relação percebida por nós, no texto, entre teoria e prática pedagógica. Essa relação se refere ao segundo movimento de interpretação que realizamos. A partir da leitura de cada resumo, fizemos um exercício de reflexão, buscando analisar em que sentido a relação teoria e prática era percebida.

Esse segundo movimento foi realizado com inspiração na noção de meta-análise, proposta por Bicudo (2014). A pesquisadora entende meta-análise como

[...] um olhar, ver, contemplar a totalidade do investigado, em uma ação que reúne, de um só golpe, a visão do todo a que se referem as análises individuais, quando se busca pela interpretação do que dizem sobre o tema investigado. Não se trata de obter uma unidade dessas diferentes análises; também não se trata de uma generalização, importante por ampliar o campo de abrangência do tema investigado. Mas, trata-se de compreender, de modo claro, o que dizem e como dizem. Trata-se 
de analisar sua consistência, esta olhada como coerência entre a pergunta disparadora da investigação, 'o quê' do investigado, os procedimentos de pesquisa e as interpretações efetuadas (BICUDO, 2014, p. 09).

Conforme já discutido no início do texto, há possibilidades de relações no sentido da teoria para a prática e, também, no sentido inverso, da prática para a teoria. Entendemos que um mesmo trabalho possa apresentar traços dessa relação nos dois sentidos, até porque vemos teoria e prática como uma relação cíclica. No entanto, buscamos destacar, durante a análise, elementos desses trabalhos que possam exemplificar os dois movimentos. Por essa razão, não vamos classificar determinado trabalho como sendo exemplo da relação teoria para prática ou prática para teoria, pois ele pode representar ambos, dependendo do recorte analisado, mas destacamos, portanto, traços desses trabalhos que nos permitam pensar sobre os movimentos supracitados.

É importante ressaltarmos que alguns artigos publicados durante os 30 anos do Boletim versam sobre o uso de Tecnologias Digitais, o ensino e aprendizagem da Matemática, mas não identificamos neles traços de movimentos que associassem teoria e prática, no sentido apontado por nós na introdução. Dos trabalhos escolhidos, relemos seus resumos, de forma mais minuciosa. Os estudos que revelaram alguma postura teórica prévia e que foram a campo a partir de elementos derivados desta postura teórica terão partes analisadas como exemplos de relação teoria e prática no sentido da primeira para a segunda, pois revelam uma ação guiada por pesquisa, por teoria. As investigações que apresentaram caminho inverso, que discutiam determinada prática e teorizaram a partir dela, suas partes são analisadas na seção que relaciona teoria e prática no sentido da segunda para a primeira.

Posteriormente ao segundo movimento de interpretação, detalhado no parágrafo anterior, retomamos a leitura dos resumos, e, quando necessário, realizamos a leitura do próprio texto, na busca de convergências na produção analisada. Há duas seções neste artigo, apresentadas a seguir, que trazem nossas impressões e a sistematização de nosso olhar a partir do inventário que construímos. Essa sistematização ajuda a revelar de que forma a relação entre teoria e prática tem se constituído nas pesquisas sobre tecnologias inseridas no contexto da Educação Matemática.

Pode ser que o leitor esteja se questionando se apenas a leitura dos resumos, com algumas complementações dos textos na íntegra, é suficiente para que se tenha uma compreensão do material produzido no periódico relacionado às Tecnologias Digitais. Nos baseamos em Ferreira (2002) para fundamentar nossa resposta a tal questionamento. Essa pesquisadora afirma que as pesquisas de cunho bibliográfico têm o desafio de discutir a 
produção acadêmica, tentando compreender aspectos e dimensões que estejam sendo privilegiados em diferentes contextos, entre eles as publicações em determinados periódicos, como é o nosso caso. Ela também argumenta que pesquisas desse tipo são reconhecidas pela metodologia de caráter inventariante e descritivo.

Em seu artigo, discute a questão do uso de resumos para realizar pesquisas bibliográficas e, segundo ela, cada resumo pode ser

\begin{abstract}
[...] lido como um enunciado estável delimitado pela alternância dos sujeitos produtores, pela noção de acabamento de todo e qualquer enunciado e pela relação dos parceiros envolvidos em sua produção e recepção. Enquanto gênero do discurso, cada resumo é lido pelos elementos que o constituem (conteúdo temático, estilo verbal e estrutura composicional), fundidos no todo que é o enunciado. Por outro lado, assumindo o princípio de dialogismo de Bakhtin, cada resumo é lido como participante de uma cadeia de comunicação verbal, onde suscita respostas e responde a outros resumos (FERREIRA, 2002, 267).
\end{abstract}

Assim, entendemos que os resumos permitem contar uma história de determinada produção acadêmica, já que outras são possíveis (GARNICA, 2013), embora seja necessário reconhecer que eles forneçam uma história de produção acadêmica diferente da que seria contada pelos trabalhos na íntegra o que, por sua vez, também seria diferente da história narrada a partir da realidade vivida (FERREIRA, 2002). Em suma, assumimos a possibilidade de existência de diferentes histórias sobre determinada produção acadêmica e que os resumos fornecem uma delas, situada, ainda, na interpretação de quem a produziu.

\title{
4 Da prática para teoria
}

Dos textos selecionados, em dezessete identificamos características que nos permitiram pensar sobre a relação entre teoria e prática no sentido da prática para a teoria. $\mathrm{Na}$ seção de metodologia já explicamos os motivos que nos levaram a atribuir tal categoria a esses exemplos. Nesta seção vamos discutir um pouco mais que tipos de aproximações percebemos.

Duas vertentes emergiram diante dessa perspectiva. A primeira delas é composta por exemplos de trabalhos que se referiam, de alguma forma, à busca por uma aproximação de determinada realidade, o que, por sua vez, é um caso particular de buscar uma relação no sentido da prática para a teoria.

Por exemplo, Miskulin et al. (2006) analisaram e buscaram relações entre as diversas maneiras com que as escolas trabalham com a tecnologia na Educação Matemática. A pesquisa foi realizada com base na análise de questionários respondidos por professores e coordenadores. A partir disso, os pesquisadores destacaram potencialidades e limites ligados a 
dimensões implícitas ao processo de implantação de computadores nas escolas, em particular em relação ao uso desses computadores em salas de aula de Matemática. Eles inferem que, diante do avanço tecnológico, torna-se necessário uma nova cultura profissional, que deve priorizar novos conhecimentos e olhares ao processo de formação de professores. Dessa forma, a intervenção do formador acaba se ampliando na busca de novas estratégias e na criação de caminhos que favoreçam a reconstrução da prática pedagógica do professor no que se refere ao uso da tecnologia na Educação (MISKULIN et al., 2006).

Carneiro e Passos (2010), por sua vez, discutiram contribuições que um curso de Licenciatura proporcionou para a atuação de licenciados egressos em início de carreira, em particular em relação ao uso de tecnologias que esses jovens professores faziam. As concepções dos egressos foram registradas a partir de respostas a questionários e entrevistas semiestruturadas. Os autores do trabalho apontam, como resultado, que o referido curso proporcionou o contato com ambientes de discussão sobre potencialidades, dificuldades e limites que se encontram na utilização de recursos tecnológicos com fins pedagógicos a partir de algumas disciplinas cursadas. Eles apontam, também, que há indícios de impactos positivos na prática pedagógica dos professores a partir do ambiente de discussão criado na universidade, que envolveu, além das discussões já citadas, pesquisas, análise e manuseio de softwares, vídeos e outras atividades voltadas para o ensino de Matemática, além da elaboração de aulas simuladas com uso de tecnologias.

Araújo (2003) realizou uma discussão relacionada à receptividade aos computadores e às situações reais de um grupo de alunas de Cálculo I de uma universidade. Os dados consistiram em registros do trabalho do grupo de alunas para desenvolver um projeto de modelagem, proposto pelo professor da disciplina, utilizando o conteúdo de Cálculo e o software Maple. A partir dessa análise, a pesquisadora conclui que a proposição de tal projeto pressupôs um convite ao uso de computadores e às situações reais, já que o projeto envolvia, também, o uso de modelagem. No episódio analisado no artigo, no entanto, o trabalho desenvolvido pelo grupo sugere que o convite especial foi aceito em relação aos computadores, mas não em relação às situações reais. A pesquisadora conjectura que uma possível causa possa ser a experiência escolar prévia dos alunos, que, em geral, não pressupõe o estudo de situações reais de interesse deles, mas, sim, de situações reais com um objetivo maior de motivação para a aprendizagem matemática, que nem sempre surte o efeito desejado.

Nesses três exemplos, os autores buscam conhecer determinada realidade a partir de uma análise sobre a mesma, seguindo de uma teorização sobre ela. Diante disso interpretamos 
que seriam exemplos de relação entre teoria e prática do sentido da prática para a teoria, uma vez que não se realizou trabalho de campo para constatar determinada hipótese teórica, por exemplo. Pelo contrário, foi-se a campo e, a partir das experiências vividas pelos autores, teorizou-se sobre temas da área de Educação Matemática com foco no uso de tecnologias. Ainda nos três exemplos, destacamos que o contexto das realidades analisadas era presencial. Os cinco trabalhos restantes, apresentados a seguir, voltaram-se para o contexto virtual.

Pasqualotti e Freitas (2001) analisaram o uso de Ambientes Virtuais (AV) nãoimersivos $^{3}$ com foco na aprendizagem e no ensino de Matemática. Os autores investigaram experiências e condições necessárias para uso da Virtual Reality Modeling Language na Educação Matemática, em particular no desenvolvimento de aspectos cognitivos e lógicomatemáticos e na construção de conhecimento. Pasqualotti e Freitas (2001) evidenciam que o trabalho realizado por eles favoreceu a experiência de primeira-pessoa por parte dos alunos, que consiste em geração de conhecimento de forma direta e pessoal, o que não ocorre, segundo eles, em ambientes de ensino formais, caracterizados por experiências de terceirapessoa, isto é, conhecimento ensinado por alguém. Tais experiências de primeira-pessoa, segundo eles, ajudam os estudantes a aprenderem a aprender sobre um conteúdo específico de Matemática.

Bairral (2004) relata contribuições das teleinterações para o desenvolvimento docente. O estudo consiste em um recorte de uma pesquisa mais ampla, que busca analisar a importância da mediação pela internet para a formação continuada em Geometria. Particularmente no artigo, o autor caracteriza o discurso da teleinteração em um chat e destaca dificuldades que são inerentes ao contexto. Em seguida, relata momentos reflexivos vivenciados e cita exemplos de como o conhecimento profissional pode se ressignificar no contexto da teleinteração a partir de ações colaborativas. Em suas conclusões, o autor aponta para contribuições e singularidades do processo interativo nos chats.

Miskulin et al. (2011) discutem aspectos da colaboração na virtualidade. Os autores, a partir de experiências vivenciadas durante cursos realizados online, discutem sobre como a colaboração acontece na virtualidade e qual sua contribuição para resultados mais efetivos em se tratando de aprendizagem compartilhada. Também debatem sobre a redução do isolamento potencial do aluno/professor que pode ocorrer em ambientes virtuais com pouca interação. Para os autores, ao aprenderem juntos, professor e alunos têm a oportunidade de aprofundar e até superar problemas relacionados às suas experiências de aprendizagem, vivenciando e

\footnotetext{
${ }^{3}$ Os autores consideram este ambiente como sendo aquele onde o utilizador não tem a sensação de inclusão experimentada, ou seja, ele não se sente dentro do ambiente.
} 
compartilhando ideias e, também, recebendo retorno crítico e construtivo. Ainda, segundo Miskulin et al (2011), a virtualidade promove espaços formativos de professores que ensinam Matemática a partir do momento em que a colaboração é vista como fator essencial para construção e compartilhamento de significados e experiências relacionados à prática docente.

Viseu e Ponte (2012) analisam o papel das Tecnologias da Informação e Comunicação (TIC) na discussão virtual de situações de sala de aula relacionadas ao estágio de futuros professores de Matemática. O trabalho envolveu a análise de material registrado no fórum e em e-mail, além da análise de entrevistas realizadas no início e ao final do período de estágio de três alunos de licenciatura alocados em diferentes escolas. Os autores inferem que as TIC permitiram o compartilhamento e a discussão de situações de sala de aula e o trabalho entre estagiários e seus respectivos orientadores. A comunicação registrada foi além da unidirecional e a reconstrução de alguns momentos, acompanhada de interpretações e problematizações sobre os mesmos, contribuíram para que os licenciandos olhassem para a própria prática como recurso para aprender a ensinar.

Melillo e Kawasaki (2013), a partir da análise do uso de tecnologias em mediações virtuais de professores de Matemática em transição da modalidade presencial para a virtual, elaboram um guia que pode os auxiliar nessa tarefa. Situadas no contexto da Universidade Aberta do Brasil (UAB), as autoras tiveram uma preocupação com o processo de transição de profissionais que atuam na modalidade presencial para atuação na virtual sem, muitas vezes, passarem por capacitações prévias. A partir da observação de como esses profissionais mediavam a aprendizagem dos estudantes, as pesquisadoras constataram que, em diversas situações, os recursos disponíveis eram utilizados de forma precária. Com base na Teoria da Atividade, que estuda o sujeito em atividade, elaboraram um guia que pudesse auxiliar os professores que passam por esse momento de transição repentina, procurando esclarecer a esse profissional os elementos que constituem a UAB, e sugerindo ferramentas e tutorias para a realização de tarefas de mediação.

Nesses cinco novos exemplos, também percebemos uma tentativa de aproximação e compreensão de determinada realidade, agora ligada ao contexto virtual. Assim, dos oito trabalhos apresentados nesta primeira vertente, mais da metade se referem ao contexto virtual. São trabalhos publicados a partir de 2004, ano em que o Boletim já completava quase vinte anos. Conjecturamos que essas características peculiares de número expressivo e recente sejam naturais pelo fato de $\mathrm{a} \mathrm{ED}$ ser uma modalidade de educação relativamente recente para a qual, em geral, os professores que nela atuam não recebem formação direcionada. Assim, uma alternativa de se pensar em ações futuras é conhecer por meio de pesquisas o que vem 
sendo feito, para que se possa analisar práticas e refletir sobre a consonância entre elas e as visões relacionadas aos processos educacionais presentes tanto entre quem trabalha com a modalidade quanto entre quem pesquisa sobre ela.

$\mathrm{Na}$ segunda vertente das pesquisas que relacionam teoria e prática no sentido da prática para a teoria estão nove exemplos, presentes em mais alguns trabalhos. Em todos eles foi percebido um elemento comum: uma análise de alguma intervenção que seja uma alternativa para a sala de aula tradicional e que se utilize das Tecnologias Digitais para tal. Nesse caso, também temos um caso particular de relação entre teoria e prática no sentido da ação para a pesquisa, mas o que difere estes exemplos dos oito anteriores é que os próprios pesquisadores, no caso, realizaram intervenções e, posteriormente, as analisaram. Ou seja, é compreensão de uma ação, mas não uma ação que emerge naturalmente e é realizada por atores externos à pesquisa, mas, sim, aquela provocada diretamente pelo pesquisador a partir de suas concepções prévias e de sua intervenção.

Santos e Magina (2008) analisaram as estratégias de manipulação de dados na formação de conceitos estatísticos elementares de uma professora das séries iniciais. O trabalho foi realizado a partir da análise de um curso de formação continuada realizado em uma escola pública, e, também, da análise de encontros individuais. O tema em questão foi a manipulação e representação de dados no ambiente computacional. Os resultados, segundo as autoras, apontaram para uma preferência, por parte da referida professora, pela leitura de gráficos como se fossem tabelas simplificadas, evitando, dessa forma, uma representação icônica. A rejeição da professora pelo modo gráfico foi interpretada pelas autoras como resultado da pouca familiaridade com a tecnologia que tinha em mãos, que, a saber, era o software Tabletop, criado especificamente para manipulação de dados.

Rosa e Viali (2008) analisaram o uso da planilha eletrônica como recurso pedagógico no ensino de números racionais na Educação Básica. O estudo foi realizado visando a exploração de associações entre as representações numéricas e decimais dos números racionais com alunos da sexta série de duas turmas de uma escola pública de Porto Alegre. Um questionário inicial foi aplicado para traçar o perfil de cada turma, e utilizado para comparação de dados, já que em uma turma o conteúdo foi trabalhado de forma convencional, com giz e lousa, e, na outra, foram utilizadas as planilhas eletrônicas. Testes de múltipla escolha foram realizados em ambas as turmas para comparação entre o número de acerto e erros. Um segundo teste foi aplicado cinco meses após o primeiro. A partir do perfil traçado inicialmente, os pesquisadores tentaram relacionar características pessoais dos perfis dos alunos com o número de acertos do mesmo em cada teste. Por exemplo, ter computador em 
casa se mostrou como uma variável que influencia o sucesso, ou não, do aluno ao responder uma questão. Outros elementos, como motivação e entusiasmo, também foram associados à turma que trabalhou com computadores.

Ferreira, Soares e Lima (2009) investigaram contribuições dos ambientes de geometria dinâmica na formação de professores de Matemática. Os pesquisadores, considerando a demonstração como peça importante na construção do conhecimento geométrico, realizaram uma intervenção a partir da qual desenvolveram uma proposta de uso de ambiente de geometria dinâmica em demonstrações de resultados geométricos. Segundo os autores, características peculiares desses ambientes, como a possibilidade de experimentar, conjecturar, visualizar, entre outras, favorecem a diminuição de dificuldades enfrentadas na passagem do conhecimento de natureza empírica para o de natureza formal. Para inferir que o ambiente favoreceu tal passagem, os autores analisaram os níveis de desenvolvimento do raciocínio geométrico, propostos por Van Hiele, antes e após a execução das atividades propostas.

Dullius, Araujo e Veit (2011) investigaram a aprendizagem de equações diferenciais por meio de situações-problemas exploradas utilizando o computador. Os autores buscaram, em sua intervenção, contemplar não apenas a resolução analítica das equações, mas, também, a interpretação delas próprias e de suas soluções. O trabalho foi conduzido com o auxílio de um software que permite a modelagem de um sistema de equações diferenciais por meio da elaboração de diagramas de fluxo. Com isso, não há necessidade de conhecer a solução analítica da equação para que seu comportamento seja estudado. Após a análise de dados produzidos com a participação de alunos de graduação de cursos de Engenharias e Química Industrial, os pesquisadores concluíram que a proposta se mostrou viável em termos de se buscar uma aprendizagem significativa do conteúdo, mas notaram certa resistência por parte dos alunos em se trabalhar com metodologia que foge do sistema tradicional.

Souza e Lopes (2011) buscaram uma compreensão de contribuições das tecnologias na educação estocástica. A pesquisa enfatizou atividades relacionadas ao estudo probabilístico realizado com quatro alunas voluntárias de uma escola municipal de São José dos Campos. O software utilizado nas atividades foi o Fathom, no qual os autores reconhecem um grande potencial para o ensino de Estatística e Probabilidade. Na pesquisa eles o utilizaram como simulador de eventos aleatórios. O processo centrou-se na interação, com dimensão coletiva e com apoio de recursos tecnológicos. Para os autores, tornou-se evidente que o uso de recursos desse tipo aumenta a amplitude e a precisão dos conhecimentos construídos, mas, por outro lado, exige que o professor tenha um domínio mais amplo do conteúdo que está ensinando. 
Outro elemento, que também se destacou na análise, foi a importância da simulação e do processo de interação na educação estocástica.

Diniz e Borba (2012) analisam a leitura e interpretação de dados prontos extraídos da internet por alunos ao desenvolverem projetos de modelagem. Por dados prontos os autores entendem informações coletadas da internet, já organizadas, que nem sempre explicam como essas etapas foram realizadas. Por exemplo: uma fórmula pronta para descrever determinado fenômeno sem o acompanhamento de uma explicação que leve o leitor a entender como se chegou a determinada expressão. Os autores buscaram compreender como os alunos apresentam e interpretam esse tipo de dado em relatórios escritos e orais de projetos de modelagem. Após a análise, perceberam que os dados prontos parecem ser tratados da mesma forma que os empíricos, ou seja, sem questionamentos em relação ao percurso que levou a determinado gráfico ou fórmula. Nesse ínterim, destaca-se o papel do professor como alguém que pode provocar uma leitura por parte dos alunos para além dos dados.

Gonçalves e Reis (2013) realizaram uma pesquisa que buscava construir, por meio de atividades investigativas utilizando o software Geogebra, uma abordagem para aplicações de derivadas. No artigo, os pesquisadores apresentam um produto educacional que foi resultado de sua intervenção, que consiste em um guia de atividades sugeridas. Eles discutem a opção pelo uso das atividades investigativas, situando essa abordagem no contexto das mudanças que podem ocorrer em sala de aula com a inserção de tecnologias. A descrição do produto educacional é seguida de considerações tanto sobre sua aplicação quanto de contribuições percebidas para os processos de ensino e aprendizagem de Cálculo I, destacando-se contribuições para: 1) a ressignificação dos conceitos dos alunos em relação ao tópico abordado, 2) a criação de um ambiente de aprendizagem complementar e diferenciado se comparado à sala de aula usual, e 3) a formação do professor de Matemática dos ensinos Fundamental e Médio.

Lopes (2013), em perspectiva semelhante à pesquisa citada no parágrafo anterior, também apresenta um produto educacional com sugestões de atividades. Nesse caso, no entanto, trabalham-se atividades investigativas com uso do Geogebra para o conteúdo de trigonometria. A autora analisa limitações e potencialidades de sua proposta para os processos de ensino e de aprendizagem desse conteúdo, levando em consideração a participação de alunos do ensino médio. As concepções da Didática da Matemática são utilizadas para tratar, de forma teórica, o uso pedagógico de tecnologias. Dentre as potencialidades destacadas na análise de dados estão a possibilidade de construção, o dinamismo, o caráter investigativo, a visualização e a possibilidade de argumentação. As limitações ficaram mais ligadas à 
infraestrutura do laboratório e à falta de conhecimento, por parte dos professores da escola, em relação ao sistema operacional instalado nos computadores.

Por fim, Isotani e Brandão (2013) discutem experiências realizadas em cursos de licenciatura e de extensão universitária utilizando o software iGeom. Os autores debatem o papel de destaque da Geometria Interativa quando se ensina Geometria a partir do uso de computadores. Por Geometria Interativa eles entendem a Geometria implementada por computador, na qual é possível movimentar objetos sem que os vínculos estabelecidos durante a construção sejam perdidos, o que entendemos estar relacionado à ideia de Geometria Dinâmica. Segundo os autores, as contribuições aparecem tanto para professores quanto para alunos. Assim, se por um lado ela ajuda o professor na criação de material didático interativo e que desperte a curiosidade, por outro proporciona ao aluno um ambiente que estimula a postura participativa e a busca por desafios, passando pela troca de experiências e pela maturidade na compreensão de um conteúdo geométrico.

Os nove trabalhos trazem uma análise a partir de alguma experiência envolvendo o uso de tecnologias. Percebe-se uma variedade de referenciais teóricos, de procedimentos metodológicos para realizar o processo analítico e de recursos tecnológicos utilizados na experiência, mas há um fio condutor que une os trabalhos: a busca pela superação da crise que enfrentamos, há décadas, no ensino de Matemática, seja na educação básica ou na formação inicial e continuada de professores (D’AMBRÓSIO; BORBA, 2010). As tecnologias digitais, a depender da forma como são utilizadas, podem ser um recurso para minimizar os problemas enfrentados nessa disciplina, dado o amplo leque de possibilidades que se abrem a partir de sua utilização, em especial as ligadas à dinamicidade, ao feedback e à visualização. As pesquisas citadas nessa segunda vertente buscam na intervenção empírica uma relação entre prática e teoria, nesse sentido.

Notamos que nenhum dos trabalhos apresentados na segunda vertente que relaciona teoria e prática no sentido da prática para a teoria desenvolveu-se no contexto da modalidade de ensino a distância. Acreditamos que isso reforça nossa conjectura de que o caminho seguido pelos pesquisadores da área tem sido conhecer o que vem sendo feito em termos de práticas pedagógicas antes de, de fato, pensar em intervenções direcionadas.

\section{Da teoria para a prática}

Nesta seção apresentamos os textos encontrados nesses trinta anos de BOLEMA nos quais os autores fazem uso de algumas pesquisas realizadas para direcionar suas ações, no que 
diz respeito ao uso das TD no ensino e na aprendizagem da Matemática, em todos os seus níveis. Diferentemente de como fizemos na seção anterior, decidimos agrupar os textos, aqui, de acordo com a tecnologia utilizada ou a forma com que esse uso foi realizado, para que o leitor possa ver, de forma mais clara, como as práticas ocorreram a partir de algumas pesquisas realizadas preliminarmente. Por exemplo, tomamos o primeiro texto publicado nessa vertente, qual seja, Borba (1994).

Nesse trabalho, o pesquisador discute como o uso de representações múltiplas afeta o ensino e a aprendizagem da Matemática. Além disso, o autor analisa como um estudante constrói "conhecimento ao utilizar um aplicativo para funções com representações como tabelas, gráficos cartesianos, álgebra e calculadora" BORBA (1994, p.1). O pesquisador se fundamenta em autores da área que apontam que o papel predominante da Álgebra na Educação Matemática causa dificuldades de aprendizagem, uma vez que os alunos não conseguem associar significados desenvolvidos por eles mesmos em outros contextos que não sejam essencialmente algébricos. O pesquisador parte, então, de resultados de pesquisas para propor uma intervenção que integra diferentes representações relacionadas às funções. Para isso, ele utiliza um software com suporte a tabelas, gráficos e elementos algébricos.

O olhar para a aprendizagem constitui a maior parte dos trabalhos desta seção. Também, levando em consideração diversas pesquisas acerca do uso de algumas mídias no ensino da Matemática, Scheffer (2003) utilizou a ideia de representações múltiplas para promover uma discussão com alunos da $8^{\text {a }}$ série (hoje, $9^{\circ}$ ano do Ensino Fundamental) de uma escola pública no estudo de movimentos corporais. Em sua pesquisa, a autora fez uso de diferentes mídias para obter essas representações, como calculadora, computador, papel e lápis, além das manifestações orais dos estudantes que participaram da pesquisa e que, segundo Scheffer (2003), desencadearam um aprofundamento teórico dos temas.

A calculadora, presente nos dois estudos anteriores, durante muito tempo foi alvo de pesquisas que envolviam (ou não) a prática em sala de aula, como podemos observar no trabalho de Karrer e Magina (2000), onde as autoras realizaram um estudo preliminar sobre o uso dessa mídia em aulas de Matemática, além de um levantamento histórico acerca de logaritmos e a dificuldade no ensino e na aprendizagem desse conteúdo. Em seguida, desenvolveram uma sequência de ensino sobre logaritmos, baseada em situações-problemas envolvendo equações exponenciais, integradas ao uso de calculadoras com quatro alunas do primeiro ano do Ensino Médio de uma escola particular. Segundo Karrer e Magina (2000), a calculadora, vista inicialmente como algo desnecessário, funcionou como uma facilitadora 
nos cálculos em uma sequência de ensino que permitiu uma maior assimilação dos conceitos de logaritmo.

Com a chegada dos computadores às residências e escolas, abastecidos por diversos softwares educacionais, as pesquisas associadas a eles passaram a ganhar espaço no universo da Educação, em particular da Educação Matemática. Algumas delas buscavam investigar de que forma um software específico poderia contribuir em uma disciplina ou projeto, como podemos observar na pesquisa de Lira e Monteiro (2011). Esses autores investigaram a interpretação de dados com o auxílio do software TinkerPlots, em pesquisa realizada com 12 estudantes do $7^{\circ}$ ano do Ensino Fundamental. Ao utilizar as ferramentas presentes no software, os estudantes organizaram os dados de forma a obterem diferentes maneiras de representações gráficas para realização da interpretação destes. Segundo Lira e Monteiro, isso possibilitou que os estudantes abordassem esses dados de maneira ativa, estabelecendo interpretações que consideravam diversos aspectos das relações entre estes.

Abar e Alencar (2013) apresentam em seu texto os resultados de uma pesquisa que tinha como objetivo o desenvolvimento de uma oficina de formação continuada, com o uso do GeoGebra, para professores de Matemática da escola básica. Cursos (ou oficinas) dessa natureza, em geral, proporcionam a esses professores o contato com uma tecnologia que não lhes foi apresentada durante sua formação inicial ou, no caso onde o contato existiu, este se deu de maneira superficial. A inserção de um recurso tecnológico na prática pedagógica do professor de Matemática ainda é um grande desafio mencionado por pesquisadores como Abar e Alencar (2013), pois, em muitos casos, os professores têm a impressão que esse recurso, por si só, já é um motivador. Entretanto, caso a proposta de trabalho com a sua utilização não se mostre interessante aos alunos, essa motivação será perdida de forma muito rápida, o que demonstra a importância, citada também pelos autores, de cursos de formação continuada que não apenas apresentem a esses professores as possibilidades desses softwares, mas, também, que possam aprimorar suas interpretações ou formas de pensar a Matemática a partir do contato com tais tecnologias.

Softwares algébricos também surgem nos textos encontrados nos trinta anos do BOLEMA. Dazzi e Dullius (2013), por exemplo, utilizaram o software Graphamatica para desenvolverem uma ação pedagógica com 150 alunos do $3^{\circ}$ ano do Ensino Médio no estudo de funções polinomiais. Segundo os autores, a abordagem do conteúdo de funções polinomiais de grau maior que dois, pela forma algébrica, exige muito tempo em sala de aula. Além disso, os gráficos das funções esboçados pelos alunos em seus cadernos podem não apresentar exatidão, interferindo na análise de suas propriedades, levando-se em conta a 
evidência das dificuldades que muitos alunos apresentam na resolução de exercícios envolvendo gráficos.

Outro software algébrico utilizado foi o Winplot. Mota e Laudares (2013) utilizaram o software em conjunto com as mídias lápis e papel em uma sequência didática que articulava teoria e prática, privilegiando o tratamento gráfico, utilizando seções transversais e curvas de níveis, com o objetivo de possibilitar aos estudantes o esboço de gráficos de funções e o estudo de planos, cilindros e quádricas. Os autores afirmam que foi evidente a forma como os estudantes realizaram as representações gráficas, suas reflexões, dúvidas e resultados. Também, puderam verificar uma melhora significativa na postura dos mesmos, pois esses se demonstraram mais ativos no processo de aprendizagem. Foi observado, ainda, que a articulação entre a equação (álgebra) e a figura (geometria) promoveu uma abordagem integrada entre Álgebra e Geometria, que é o foco da Geometria Analítica.

Além de investigações relacionadas ao uso de softwares destinados ao ensino e a aprendizagem da Matemática, outros textos encontrados por nós, dentre os selecionados, se remetem ao uso de softwares que auxiliam o professor em outras tarefas de seu dia a dia. Por exemplo, (BARROSO et al., 2009) propuseram, em seu trabalho, um método de realimentação para o processo de avaliação com o apoio de ferramentas computacionais. Os autores apresentaram uma aplicação desse método em sala de aula, na qual as atividades propostas aos alunos foram fundamentadas em teorias da Didática da Matemática e elaboradas em um programa de computador que faz o rastreamento das atividades dos estudantes. A partir da análise do comportamento do professor, nessa experimentação em que ficaram expostas as suas dificuldades naturais em modificar os seus hábitos de ensino, destacaram a necessidade de um trabalho de educação em conjunto, envolvendo, também, a participação de pesquisadores da área de Educação Matemática e de profissionais da área de Informática como suporte ao trabalho do professor.

Costa e Fiorentini (2007) investigaram indícios de mudança da cultura e desenvolvimento docente em uma escola pública, em um contexto onde professores de Matemática da escola formaram um grupo colaborativo, visando introduzir as TIC em suas práticas pedagógicas. Em seu artigo, os autores abordam o caso específico de uma professora participante que foi entrevistada e observada em sua prática docente e nos encontros do grupo. O estudo mostrou que a utilização das TIC no ensino de Matemática, mediada pela colaboração, desencadeou um processo catalisador do desenvolvimento profissional da professora e de mudanças na cultura de seu trabalho docente. Nesse cenário, a professora se viu mais interativa, já que, com as TIC, foram ampliadas as possibilidades de compartilhar 
experiências e saberes com outros docentes, podendo, assim, acompanhar o desenvolvimento de seu campo profissional e, também, levar seus alunos a terem acesso e interlocução com os saberes disponíveis na Web.

Ao analisarmos os textos publicados no Boletim, nos chamou a atenção a importância dada à colaboração quando estávamos diante de trabalhos inseridos no contexto da Educação a Distância (EaD). Tractenberg, Barbastefano e Struchiner (2010) analisaram uma experiência de Ensino Colaborativo Online em uma disciplina de Geometria. Segundo eles, o ensino colaborativo (EC) e o ensino colaborativo online (ECO) podem contribuir para romper a cultura de isolamento docente, favorecer o desenvolvimento dos professores, a implementação de práticas pedagógicas inovadoras e a aprendizagem dos alunos. Eles analisaram uma experiência de ECO de Geometria, buscando identificar como nela se faziam presentes as contribuições do EC para o ensino da Matemática, e de que forma as TIC utilizadas contribuíram para a efetividade dessa experiência.

Em um caminho contrário, possibilidades geradas pela Educação a Distância são exploradas, também, pelo ensino presencial. Em seu artigo, Groenwald, Zoch e Homa (2009) apresentaram o resultado de uma investigação acerca da implementação de conteúdos online em uma disciplina presencial de um curso de Licenciatura em Matemática, mais especificamente os conteúdos de Análise Combinatória. Segundo eles, a proposta de elearning em uma sala de aula presencial permitiu a construção de conceitos de maneira colaborativa pelos alunos.

Já Santos, Miarka e Siple (2014) discutiram a utilização de blogs, entendidos como uma Tecnologia da Informação e da Comunicação narrativa, como um dos instrumentos de avaliação da disciplina de Estágio Curricular Supervisionado do curso de Licenciatura em Matemática, de uma universidade pública brasileira. Para isso, apresentaram e discutiram elementos relacionados à escolha do blog, como uma tecnologia educacional narrativa, aplicada em processos de avaliação e reflexão da prática docente dos estagiários. Em seguida, a partir da análise dos blogs relativos aos estágios dos alunos participantes da disciplina, articularam categorias que dizem da experiência docente na formação inicial. Os autores discutiram, também, o uso dos blogs como recurso metodológico, ora como possibilidade de os alunos estagiários se narrarem, ora como possibilidade de narrarem sobre a prática do ser professor.

Por outro lado, Monzon e Gravina (2013) nos trazem a concepção e a construção de produto educacional que trata de números complexos e funções. Nessa concepção, levou-se em consideração o importante papel que tem os sistemas de representação semiótica no 
processo de aprendizagem da Matemática. A construção resultou na publicação de um site contendo uma coletânea de animações interativas que fazem uso de sistemas dinâmicos de representação algébrica e geométrica. O produto foi testado com turma de alunos do terceiro ano do ensino médio e os resultados obtidos mostram que, com o apoio de ferramentas digitais de mediação semiótica, é possível não só introduzir novos conteúdos no programa da matemática escolar, mas, também, novas propostas de ensino.

Outros aspectos das TD são encontrados nas pesquisas aqui relatadas. Scucuglia (2014) apresenta um estudo no qual foram investigadas as imagens sobre matemáticos em um contexto no qual estudantes de graduação se engajaram na produção de performances matemáticas digitais (PMD). Para o desenvolvimento de sua pesquisa, Scucuglia realizou um curso de extensão universitária no qual os estudantes produziram duas PMD, uma de natureza cinematográfica e outra musical. Com a pesquisa, o autor oferece meios para a desconstrução de imagens estereotipadas sobre a Matemática e os matemáticos e fomenta a construção de imagens alternativas nos cenários educacionais e sociais enfatizando as artes e o uso de Tecnologias Digitais.

Ainda encontramos o trabalho de Maciel e Cardoso (2014), que relatam uma pesquisa em que buscaram promover uma aprendizagem significativa de função. Os autores utilizaram a História da Matemática como estratégia de ensino e o vídeo como recurso didático. A metodologia consistiu em pesquisa bibliográfica, criação de roteiro, pesquisa iconográfica, produção e edição de quatro vídeos e aplicação em sala de aula. Também, foi construído um caderno de atividades para aprofundar a temática. Segundo eles, a utilização do vídeo, como um recurso didático, evidenciou que os alunos são atraídos por esse tipo de mídia, tornandoos mais receptivos aos novos conteúdos, já que, submetidos à exibição do vídeo, interessaram-se pelo conteúdo e pelo fato de ter sido construído com auxílio de outros alunos do Ensino Médio.

A relação entre o conteúdo matemático abordado e um tema pode se mostrar crucial no momento da escolha e do desenvolvimento de uma atividade matemática. Por exemplo, Pinheiro e Bazzo (2009) fazem uma reflexão acerca da inserção de temas que permitam abordar a Matemática por meio de suas relações com o contexto científico-tecnológico e social. A pesquisa foi desenvolvida sob os pressupostos da Educação Matemática Crítica, e teve como público-alvo alunos do primeiro ano do Ensino Médio, na disciplina de Matemática. A questão-problema que norteou o estudo foi a possibilidade de introduzir no ensino e na aprendizagem da Matemática, pesquisa, leitura e casos simulados que pudessem aproximar o conhecimento matemático do contexto científico-tecnológico e social, permitindo 
ao aluno questionar, refletir e avaliar a influência e dependência da Matemática, enquanto ciência, frente aos demais conhecimentos. Segundo os autores, a análise dos dados apontou para a pertinência de introduzir, além do conhecimento matemático formal, a pesquisa, discussões e os casos simulados em sala de aula, como forma de romper o tradicionalismo e promover uma nova forma de construir o conhecimento, destacando as possibilidades de avanços e limitações que os diferentes saberes possuem.

Azevedo, Puggian e Friedmann (2013) realizaram uma proposta integrada para a formação continuada de professores, no caso, alunos de Mestrado Profissional em Matemática, associando a criação de um site para a construção de WebQuests, oficinas interativas e de um guia de apoio para o uso de Tecnologias da Informação e Comunicação nas aulas de Matemática. Segundo os autores, os resultados de sua pesquisa indicaram que há a necessidade de que os produtos educacionais desenvolvidos pelos participantes da pesquisa, por meio de propostas integradas, devam considerar, também, a aprendizagem dos conceitos matemáticos pelos próprios professores.

Por fim, temos a pesquisa de Dalla Vechia e Maltempi (2012), na qual os autores construíram um entrelaçamento teórico-filosófico que tinha como objetivo discutir a relação entre a Modelagem Matemática e realidade do mundo cibernético. Em particular, essa abrangência da realidade foi evidenciada como um possível vetor de virtualização, ou seja, como um aspecto que pode influenciar o modo como a problemática que envolve uma determinada situação ou entidade é compreendida. Para tanto, os autores fizeram uma associação entre a Modelagem Matemática e as transformações que envolvem os modos de ser denotados por real, possível, atual e virtual, tendo como base ilustrativa uma concepção de problema que permite uma consolidação entre as relações estabelecidas e, também, uma concepção de realidade que entende o mundo cibernético como uma de suas dimensões.

\section{Considerações finais}

Neste artigo, realizamos uma análise - pesquisa bibliográfica, estado da arte e metaanálise - das pesquisas relacionadas ao uso de Tecnologias Digitais na Educação Matemática brasileira, tendo como cenário de investigação as publicações presentes nos trintas anos da revista BOLEMA. Como o tema desta edição comemorativa da revista está associado à ideia de como as pesquisas se traduziram em práticas efetivas na sala de aula, presencial ou virtual, ou como elas podem ter influenciado práticas já existentes, nosso olhar abordou essa temática, sempre nos voltando para as TD na pesquisa e na prática. 
Essa iniciativa do BOLEMA nos parece fundamental, de modo a nos lembrar, mais uma vez, que uma pesquisa pura em Educação Matemática pode frustrar a dinâmica da sociedade que tem apoiado o desenvolvimento da pesquisa em geral e da pesquisa em Educação Matemática em particular. Nossa análise do que é publicado no BOLEMA, sobre as TD, mostra que, ao menos nessa área, tal tendência a valorizar uma pesquisa desvinculada da prática não acontece. Há artigos que lidam com a metodologia da pesquisa e há, também, os grandes blocos discutidos neste artigo.

Compreendemos a importância de trabalhos semelhantes aos apresentados aqui, por acreditarmos que teoria e prática devam ser indissociáveis (FREIRE, 1996), em particular na Educação Matemática. Entendemos, também, que a distinção feita por nós não é rígida e que vários pesquisadores indicam a forma de ciclo ação-pesquisa-ação, como proclama a design research (DOERR; WOOD, 2010). Assim, em alguns artigos já há os dois sentidos da investigação, embora um deles apareça com mais força na publicação, levando a nossa escolha em discuti-lo em outro bloco. Há, também, modos de compor diversas pesquisas que fogem um pouco à ideia do ciclo, e propõe como modelo um mosaico. Tal ideia, bastante presente no grupo de pesquisa GPIMEM, vê certas teses, dissertações ou investigações docentes como parte de uma pesquisa integrada, que periodicamente busca sínteses provisórias.

D’Ambrósio (1996; 2013) afirmou há 30 anos que a Educação Matemática é uma atividade multidisciplinar, com o objetivo de transmitir conhecimentos e habilidades matemáticas por meio dos sistemas educativos e que a Matemática é uma linguagem que deve estar ligada ao contexto sociocultural em que está inserida. Na visão desse autor, um especialista em sintetizar blocos de pesquisas, gerando tendências, a Educação Matemática faz sempre parte de um círculo, utilizando a terminologia dele, que inclui realidade, reflexão e ação, que é consistente com o que encontramos nesta meta-pesquisa.

Embora o primeiro número do BOLEMA tenha sido publicado em 1985, o primeiro texto publicado pelo Boletim, envolvendo pesquisas relacionadas às Tecnologias Digitais e seu uso na Educação Matemática, aconteceu quase uma década depois. Isso se deve, principalmente, ao fato de que o uso dessas mídias ainda não ocorria, de maneira intensa, dentro do cenário educacional brasileiro. Por exemplo, com relação à informática e à Educação Matemática, a interseção desses dois elementos começa a acontecer no final dos anos 1980 e início dos anos 1990, a partir de algumas políticas públicas voltadas para esse fim (BORBA; PENTEADO, 2010), e é a partir do início dos anos 2000 que percebemos uma maior frequência nas publicações englobando temáticas relacionadas às TD. Da mesma 
forma, a primeira publicação sobre educação a distância online, no BOLEMA, é de 2004, seguindo o início das pesquisas na área por parte de professores do PPGEM em 1999, que culminam com a publicação de uma seção no livro de Borba e Penteado (2010) apoiado na pesquisa de Gracias (2003). Uma análise mais geral da produção acerca das pesquisas em Educação a Distância no Brasil, pode ainda ser encontrada em Maltempi e Malheiros (2010).

Fixando nossos olhares nos artigos, podemos perceber dois grupos, constituídos por alguns subgrupos, de publicações envolvendo a teoria e a prática no ensino e na aprendizagem da Matemática nestas três décadas de BOLEMA. Esses grupos se constituíram a partir de nossas impressões sobre a maneira com que teoria e prática se relacionavam nos textos. No sentido prática para a teoria, alguns trabalhos buscavam, inicialmente, se aproximar de uma determinada realidade a partir de estudos preliminares, em seguida os autores teorizavam sobre esta realidade. Os demais trabalhos desse grupo, guiando-se em análises relacionadas a alguma intervenção, propunham alternativas para a sala de aula tradicional a partir do uso das TD. No segundo grupo de trabalhos, aquele que compreendemos se referir a um sentido de teoria para a prática, nosso olhar voltou-se para a identificação da TD utilizada e a forma com que isso ocorreu. Percebemos que boa parte desses trabalhos está voltada para a aprendizagem da Matemática, em que os autores se sustentam em pesquisas concluídas, ou ainda em andamento, para realizarem atividades com alunos.

Neste artigo, de cunho teórico, podemos perceber o quão importante é a pesquisa em Educação Matemática, como mencionado por Bicudo (1993) ao nos chamar a atenção para que a

[...] pesquisa em Educação Matemática vale. Ela permite que se compreenda a Matemática, o modo pelo qual ela é construída, os significados da Matemática no mundo. Com isso, ela presta serviço à Educação e à Matemática. À Matemática, por ajudá-la a compreender-se. À Educação, por auxiliar a ação político-pedagógica (BICUDO, 1993, p. 22).

Olhando para a prática, e para os textos apresentados aqui, a pesquisa em Educação Matemática vale ainda mais, a nosso ver, em virtude de possibilitar que seus resultados, bem como outros aspectos, possam influenciar a atuação do professor em sala de aula, na preparação e desenvolvimento de atividades, na formação continuada, entre outros fatores. Entendemos que os artigos analisados e a própria chamada deste número especial indicam que a Educação Matemática está em constante tensão entre o refletir da pesquisa e o refletir da prática por um lado, e a prática da pesquisa e a prática da Educação Matemática por outro.

\section{Referências}


ABAR, C. A. A. P.; ALENCAR, S. V. A Gênese Instrumental na Interação com o GeoGebra: uma proposta para a formação continuada de professores de Matemática. Bolema, Rio Claro, v. 27, n. 46, p. 349-365, ago., 2013.

ARAÚJO, J. L. Situações Reais e Computadores: os convidados são igualmente bem-vindos? Bolema, Rio Claro, v. 16, n. 19, p. 1-18, maio, 2003.

AZEVEDO, M, C.; PUGGIAN, C.; FRIEDMANN, C. V. P. WebQuests, Oficinas e Guia de Orientação: uma proposta integrada para a formação continuada de professores de matemática. Bolema. Rio Claro, v. 27, n. 46, p. 663-680, ago., 2013.

BAIRRAL, M. A. Compartilhando e construindo conhecimento matemático: análise dos discursos nos chats. Bolema, Rio Claro, v. 22, n. 17, p. 1-17, set., 2004.

BARROSO, N. M. C.; SOARES, J. M.; MOTA, J. C. M; NETO, H. B. Instrumentação Tecnológica e Realimentação no Processo de Avaliação para o Ensino de Matemática na Universidade: um método baseado na Engenharia Didática. Bolema, Rio Claro, v. 22, n. 34, p. 131-152, set., 2009.

BICUDO, M. A. V. Meta-análise: seu significado para a pesquisa qualitativa. Revista Eletrônica de Educação Matemática, Florianópolis, v. 9, p. 7-20, junho, 2014.

BICUDO, M. A. V. Pesquisa em educação matemática. Pró-posições, Campinas, v. 13, n. 1, p. 18-23, mar., 1993.

BICUDO, M. A. V. (Org.). Pesquisa em Educação Matemática: concepções \& perspectivas. São Paulo: UNESP, 1999.

BORBA, M. C. Computadores, Representações Múltiplas e a Construção de Ideias Matemáticas.

Bolema, Rio Claro, v. 9, n.3, p. 83-101, março, 1994.

BORBA, M. C. Humans-with-media and continuing education for mathematics teachers in online environments. ZDM Mathematics Education. Berlim. v. 44, p. 802-814, junho, 2012.

BORBA, M. C. Potential scenarios for Internet use in the mathematics classroom. ZDM Mathematics Education, Berlim, v. 41, p. 453-465, junho, 2009.

BORBA, M. C.; PENTEADO, M. G. Informática e Educação Matemática. 4. ed. Belo Horizonte: Autêntica, 2010.

BORBA, M. C.; SCUCUGLIA, R. R. S.; GADANIDIS, G. Fases das Tecnologias Digitais em

Educação Matemática: sala de aula e internet em movimento. Belo Horizonte: Autêntica, 2014.

BORBA, M. C.; VILLARREAL, M. E. Humans-With-Media and the Reorganization of Mathematical Thinking: information and communication technologies, modeling, experimentation and visualization. New York: Springer, 2005. (volume 39).

CARNEIRO, R. F.; PASSOS, C. L. B. As Concepções de Professores de Matemática em Início de Carreira sobre as Contribuições da Formação Inicial para a Utilização das Tecnologias de Informação e Comunicação. Bolema, Rio Claro, v. 23, n. 36, p. 775-800, agosto, 2010.

COSTA, G. L. M.; FIORENTINI, D. Mudança da Cultura Docente em um Contexto de Trabalho Colaborativo de Introdução das Tecnologias de Informação e Comunicação na Prática Escolar.

Bolema, Rio Claro, v. 20, n. 27, p. 1-19, maio, 2007. 
DALLA VECHIA, R.; MALTEMPI, M. V. Modelagem Matemática e Tecnologias de Informação e Comunicação: a realidade do mundo cibernético como um vetor de virtualização. Bolema, Rio Claro, v. 26, n. 43, p. 963-990, ago, 2012.

D’AMBRÓSIO, U. Da realidade à ação — reflexões sobre educação e matemática. Campinas: UNICAMP, 1996.

D’AMBRÓSIO, U. Educação Matemática: da teoria à prática. 36. ed. São Paulo: Papirus, 2013.

D’AMBRÓSIO, U.; BORBA, M. C. Dynamics of change of mathematics education in Brazil and a scenario of current research. ZDM Mathematics Education, Berlim, v. 42, p. 271-279, jun., 2010.

DAZZI, C. J.; DULLIUS, M. M. Ensino de Funções Polinomiais de Grau Maior que Dois Através da Análise de seus Gráficos, com Auxílio do Software Graphmatica. Bolema, Rio Claro, v. 27, n. 46, p. 381-398, 2013.

DINIZ, L. N.; BORBA, M. C. Leitura e Interpretação de Dados Prontos em um Ambiente de Modelagem e Tecnologias Digitais: o mosaico em movimento. Bolema, Rio Claro, v. 26, p. 163-190, ago., 2012.

DOERR, H. M.; WOOD, T. Pesquisa-Projeto (design research): aprendendo a ensinar Matemática. In: BORBA, M. C. (Org.). Tendências Internacionais em Formação de Professores de Matemática. 2. ed. Belo Horizonte: Autêntica, 2010. 113-130.

DULLIUS, M. M.; ARAUJO, I. S.; VEIT, E. A. Ensino e Aprendizagem de Equações Diferenciais com Abordagem Gráfica, Numérica e Analítica: uma experiência em cursos de Engenharia. Bolema, Rio Claro, v. 24, n. 38, p. 17-42, abril, 2011.

FERREIRA, E. B.; SOARES, A. B.; LIMA, J. C. As Demonstrações no Ensino da Geometria: discussões sobre a formação de professores através do uso de novas tecnologias. Bolema, Rio Claro, v. 22, n. 34, p. 185-208, fev., 2009.

FERREIRA, N. S. As pesquisas denominadas "estado da arte". Educação e Sociedade, Campinas, v. 79, n. Ano XXIII, p. 257-272, agosto, 2002.

FREIRE, P. Pedagogia da Autonomia: saberes necessários à prática educativa. 1. ed. São Paulo: Paz e Terra, 1996.

GARNICA, A. V. M. História Oral e Educação Matemática. In: BORBA, M. C.; ARAÚJO, J. L.

(Org.). Pesquisa Qualitativa em Educação Matemática. 5. ed. Belo Horizonte: Autêntica, 2013. p. 87-110.

GONÇALVES, D. C.; REIS, F. S. Atividades Investigativas de Aplicações das Derivadas Utilizando o GeoGebra. Bolema, Rio Claro, v. 27, n. 46, p. 417-432, ago., 2013.

GRACIAS, T. A. A natureza da reorganização do pensamento em um curso a distância sobre Tendências em Educação Matemática. 2003. 165 f. Tese (Doutorado em Educação Matemática) Instituto de Geociências e Ciências Exatas, Universidade Estadual Paulista "Júlio de Mesquita Filho", Rio Claro, 2003.

GROENWALD, C. L. O.; ZOCH, L. N.; HOMA, A. I. R. Sequência Didática com Análise Combinatória no Padrão SCORM. Bolema, Rio Claro, v. 22, n. 34, p. 27-56, dez., 2009.

ISOTANI, S.; BRANDÃO, L. O. O papel do professor e do aluno frente ao uso de um software de geometria interativa: iGeom. Bolema, Rio Claro, v. 27, n. 45, abril, 2013. 
JAVARONI, S. L.; CHINELATTO, T. G.; OLIVEIRA, F. T.; ZAMPIERI, M. T. Pesquisando sobre tecnologias informáticas nas aulas de matemática. In: CONGRESSO IBEROAMERICANO DE EDUCAÇÃO MATEMÁTICA, VII, 2013, Montevidéu. Anais... Montevideu [s.n.], 2013. s/p.

KARRER, M.; MAGINA, S. Uma seqüência de ensino para a introdução de logaritmo: estudo exploratório usando a calculadora. Bolema, Rio Claro, v. 13, n. 14, p. 18-31, 2000.

LIMA, T. C. S.; MIOTO, R. C. T. Procedimentos metodológicos na construção do conhecimento científico: a pesquisa bibliográfica. Katálysis, Florianópolis, v. 10, n. esp, p. 37-45, abr., 2007.

LIRA, O. C. T.; MONTEIRO, C. E. F. Interpretação de Dados a partir da Utilização de Ferramentas do Software TinkerPlots. Bolema, Rio Claro, v. 24, n. 40, p. 765-788, dez., 2011.

LOPES, M. M. Sequência Didática para o Ensino de Trigonometria Usando o Software GeoGebra. Bolema, Rio Claro, v. 27, n. 46, p. 631-644, ago., 2013.

MACIEL, P. R. C.; CARDOSO, T. F. L. A História do Conceito de Função em Vídeo: uma proposta para a aprendizagem. Bolema, Rio Claro, v. 28, n. 50, p. 1348-1367, dez., 2014.

MALTEMPI, M. V.; MALHEIROS, A. P. S. Online distance mathematics education in Brazil: research, practice and polic. ZDM Mathematics Education, Berlim, v. 42, p. 291-303, janeiro, 2010.

MELILO, K. M. C. F. A. L.; KAWASAKI, T. F. Kit de primeiros socorros: um guia para professores que, repentinamente, passam a atuar na EaD. Bolema, Rio Claro, v. 27, n. 46, ago., 2013.

MISKULIN, R. G. S.; PENTEADO, M. G.; RICHIT, A. MARIANO, C. R. A Prática do Professor que Ensina Matemática e a Colaboração: uma reflexão a partir de processos formativos virtuais. Bolema, Rio Claro, v. 25, n. 41, dez., 2011.

MISKULIN, R. G. S.; PEREZ, J.; SILVA, M. R. C.; MONTREZOR, C. L.; SANTOS, C. R.; TOON, E.; FILHO, P. A. L; SANTANA, P. H. O. Identificação e Análise das Dimensões que Permeiam a Utilização das Tecnologias de Informação e Comunicação nas Aulas de Matemática no Contexto da Formação de Professores. Bolema, Rio Claro, v. 19, n. 26, p. 1-16, nov., 2006.

MONZON, L. W.; GRAVINA, M. A. Uma Introdução às Funções de Variável Complexa no Ensino Médio: uma possibilidade através do uso de animações interativas. Bolema, Rio Claro, v. 27, n. 46, p. 645-661, ago., 2013.

MOTA, J. F.; LAUDARES, J. B. Um Estudo de Planos, Cilindros e Quádricas, na Perspectiva da Habilidade de Visualização, com o Software Winplot. Bolema, Rio Claro, v. 27, n. 46, p. 497-512, ago., 2013.

PASQUALOTTI, A.; FREITAS, C. M. D. Experimentação de Ambiente Virtual para Melhoria do Ensino-Aprendizagem de Matemática. Bolema, Rio Claro, v. 14, n. 16, p. 79-101, out, 2001.

PINHEIRO, N. A. M.; BAZZO, W. A. Caso Simulado no Ensino-Aprendizagem de Matemática: ensinar sob uma abordagem crítica. Bolema, Rio Claro, v. 22, n. 32, p. 101-122, abril, 2009.

ROSA, R. R.; VIALI, L. Utilizando Recursos Computacionais (Planilha) na Compreensão dos Números Racionais. Bolema, Rio Claro, v. 21, n. 31, p. 183-207, dez., 2008.

SANTOS, L. M.; MIARKA, R.; SIPLE, I. Z. O Uso de Blogs como Tecnologia Educacional Narrativa para a Forma/Ação Inicial Docente. Bolema, Rio Claro, v. 28, n. 49, p. 926-949, ago., 2014. 
SANTOS, S. S.; MAGINA, S. M. Estratégias de Interpretação Gráfica de uma Professora Polivalente ao Manipular Dados no Ambiente Computacional. Bolema, Rio Claro, v. 21, n. 29, p. 157-174, abr., 2008.

SCHEFFER, N. F. Interação de Sensores, Informática e o Corpo Próprio: uma Discussão Matemática sobre a Noção de Movimento. Bolema, Rio Claro, v. 16, n. 20, p. 37-55, set., 2003.

SCUCUGLIA, R. On the nature of students' digital mathematical performance. 2012. inserir número de páginas. Tese (Doutorado em Educação - School of Graduate and Postdoctoral Studies), University of Western Ontário, London, 2012.

SCUCUGLIA, R. R. S. Narrativas Multimodais: a Imagem dos Matemáticos em Performances Matemáticas Digitais. Bolema, Rio Claro, v. 28, n. 49, p. 950-973, ago., 2014.

SOUTO, D. L. P.; BORBA, M. C. Transformações Expansivas em Sistemas de Atividade: o Caso da Produção Matemática com a Internet. Perspectivas da Educação Matemática, Campo Grande, v. 6, p. 70-89, set., 2013.

SOUTO, D. P. L. Transformações expansivas em um curso de Educação Matemática a distância online. 2013. 279 f. Tese (Doutorado em Educação Matemática) - IGCE, Universidade Estadual Paulista "Júlio de Mesquita Filho", Rio Claro, 2013.

SOUTO, D. P. L.; ARAÚJO, J. L. Possibilidades expansivas do sistema seres-humanos-commídias: um encontro com a teoria da atividade. Tecnologias Digitais e Educação Matemática. 1. ed. São Paulo: Livraria da Física, 2013. p. 71-90.

SOUZA, L. O.; LOPES, C. E. O Uso de Simuladores e a Tecnologia no Ensino da Estocástica. Bolema, Rio Claro, v. 24, n. 40, p. 659-677, dez., 2011.

TRACTENBERG, L.; BARBASTEFANO, R.; STRUCHINER, M. Ensino Colaborativo Online (ECO): uma experiência aplicada ao ensino da Matemática. Bolema, Rio Claro, v. 23, n. 37, p. 1037 1061, dezembro, 2010.

VISEU, F.; PONTE, J. P. A Formação do Professor de Matemática, apoiada pelas TIC, no seu Estágio Pedagógico. Bolema, Rio Claro, v. 26, n. 42A, abr., 2012.

Submetido em Abril de 2015. Aprovado em Agosto de 2015. 